\title{
Validação de conteúdo de ações tático-técnicas do Teste de Conhecimento Tático Processual - Orientação Esportiva
}

\author{
Content validation of tactical-technical actions of the Tactical Procedure \\ Knowledge Test - Sporting Orientation
}

\author{
Pablo Juan Greco, ${ }^{1}$ Layla Maria Campos Aburachid, ${ }^{2 *}$ Schelyne Ribas da Silva, ${ }^{3}$ \\ Juan Carlos Perez Morales ${ }^{1}$
}

ARTIGO ORIGINAL | ORIGINAL ARTICLE

\begin{abstract}
A avaliação do nível de rendimento tático do atleta em competições, durante o processo de treino, nas fases de formação ou no alto rendimento, possibilita o aprimoramento do processo de ensinoaprendizagem nos jogos desportivos coletivos. Neste sentido, o presente estudo relata a utilização do método de validade de conteúdo para avaliar as ações na composição de um teste de orientação desportiva. Um painel de juízes avaliou as ações nos seguintes critérios: clareza da linguagem, pertinência prática e representatividade do item. A validação teórica teve como objetivo estabelecer itens para a criação do teste de conhecimento tático processual direcionado a avaliar o nível de tomada de decisão de crianças e jovens em jogos realizados com as mãos e com os pés. Os resultados demonstraram como ações desportivas podem se tornar itens validados. O procedimento se mostrou eficaz para elencar-se a ocorrência dos itens como parte da validação empírica do teste, aprovando 16 itens das 18 ações com coeficiente a partir de 0.82 . Assim, o estudo permitiu concluir que as ações tático-técnicas validadas por meio do método de validade de conteúdo avaliam o conhecimento tático processual que, como teste permitirá planificar os processos de ensino-aprendizagem da capacidade tática do rendimento desportivo.
\end{abstract}

Palavras-chave: validade dos testes, desportos, painel de juízes

ABSTRACT

The assessment of the level of tactical athlete's performance in competitions, during the training process, youth training or the sport performance allows the improvement of the teaching-learning process in team sports. Therefore this study reports the use of the content validity method with the aim of evaluating actions to compose a sporting orientation test. A panel of judges evaluated the actions regarding the following criteria: clarity of language, practical relevance and item representativeness. The theoretical validation aimed to establish items to create tactical procedure knowledge test to assess children and youth decision-making level in team sports played with hands and/or feet. The results showed how sports actions can become validate as items. The procedure was effective to outline items occurrence as part of empirical validation test approving 16 items of 18 actions with coefficient higher than 0.82 . Thus, the study shows that the technical-tactical actions validated by content validity method assess procedural tactical knowledge, which as a test will allow the processes of teaching and learning of tactical ability of sport performance.

Keywords: validity of tests, sports, panel of judges

Artigo recebido a 01.02.2013; $1^{\text {a }}$ Revisão 01.05.2013; 2 ${ }^{\text {a }}$ Revisão 01.08.2013; Aceite 03.09.2013

${ }^{1}$ Universidade Federal de Minas Gerais, Belo Horizonte - MG, Brasil

${ }^{2}$ Universidade Federal de Mato Grosso, Cuiabá - MT, Brasil

${ }^{3}$ Universidade Estadual do Centro Oeste, Paraná, Brasil

* Autor correspondente: Universidade Federal de Mato Grosso, Conselho de Ensino e Pesquisa, Av. Fernando Corrêa da Costa s/nº, Coxipó, CEP: 78060-900 Cuiaba, MT - Brasil; E-mail: lagusmar@ig.com.br 


\section{INTRODUÇÃO}

A avaliação do nível de rendimento tático do atleta em competições, durante o processo de treino, nas fases de formação ou no alto rendimento possibilita o aprimoramento do processo de ensino-aprendizagem nos jogos desportivos coletivos (JDC). O termo jogos desportivos coletivos (JDC) abrange, segundo Garganta (1995), desportos a exemplo do basquetebol, futebol, futsal, andebol e voleibol. Em tais modalidades, a ação do jogador apresenta um comportamento tático, resultante de um processo intencional dirigido e regulado psiquicamente (Nitsch, 2009).

Pode-se observar que as ações no jogo são condicionadas por pressões e restrições externas (posição e movimentos dos colegas e adversários, espaço de jogo, comportamento defensivo, relação com o objetivo/meta/alvo, trajetórias dos jogadores, trajetória e velocidade da bola, etc.) e internas (motivação, cansaço, etc.). Portanto, a capacidade percetiva e a tomada de decisão desempenham um papel crucial na aprendizagem das ações de jogo, possibilitando a apropriação do conhecimento tático declarativo e processual.

O conhecimento tático declarativo é definido como o nível de compreensão da lógica do jogo verbalmente declarado pelo jogador (Mitchell \& Oslin, 1994). O conhecimento tático processual manifesta-se quando o mesmo realiza ações em diferentes condições e situações por meio da concretização de um movimento (McPherson \& Thomas, 1989). A execução da técnica desportiva em situação de jogo surge como o resultado do conhecimento tático adquirido (processual e declarativo).

Os instrumentos existentes que avaliam o conhecimento processual de forma ampliada nos JDC intitulam-se Team Sport Assessment Procedure - TSAP (Gréhaigne et al., 1997), Game Performance Assessment Instrument (Griffin et al., 1998) e Game-test situations (Memmert \& Roth, 2003). Estes contemplam uma aferição das ações por peritos, porém não foi apresentado o ajustamento dos itens à semântica das ações táticas encontradas nos jogos como os professores/treinadores as intitulam na área desportiva. O Game-test situations avalia formas de pensamento convergente e divergente da tomada de decisão. Porém, o mesmo avalia os jogadores em ações de ataque (sem bola), não permitindo considerar a interseção das diferentes fases dos jogos desportivos coletivos, ataque, defesa e transição (Bayer, 1986), bem como a disputa pela posse da bola.

No levantamento bibliográfico realizado por Costa, Garganta, Fonseca e Botelho (2002) e complementado até o ano de 2012, na revisão realizada para o desenvolvimento deste trabalho, nos últimos 15 anos, apenas os estudos de Gréhaigne, Godbout e Bouthier (1997), Oslin, Mitchell e Griffin (1998), Memmert e Roth (2003), Blomqvist, Luhtanen, Laakso e Keskinen (2000) em badminton; Blomqvist, Vänttinen e Luhtanen (2005) em futebol e Costa, Garganta, Greco, Mesquita e Maia (2011) em futebol desenvolveram instrumentos que avaliam o conhecimento tático processual. Os demais estudos foram realizados, em sua maioria, apenas na perspetiva do conhecimento tático declarativo dos jogadores. A maior parte da amostra dos estudos foi dividida por nível competitivo, porém sem a apresentação de uma ampla visão sobre como as variáveis se comportam no decorrer dos anos de prática nas modalidades desportivas.

Nesse contexto, os testes são procedimentos avaliativos importantes do processo pedagógico, que possibilitam o levantamento de dados de determinada variável, auxiliando o professor na tomada de decisão sobre os modelos de ensino mais adequado para abordar os conteúdos e atividades planeadas (Greco, Memmert \& Morales, 2010).

Um segundo aspeto a mencionar é o facto de que muitos pesquisadores têm utilizado, principalmente, participantes adultos para identificar as características dos processos cognitivos nos desportos. Poucos são os pesquisadores que têm examinado se as diferenças nesses processos também são visíveis nos atletas jovens e, se a melhoria dos processos cognitivos também ocorre em função da maturação e 
da prática (Williams, Ward, \& Smeeton, 2004).

Objetivou-se identificar evidências de validade de conteúdo do teste para avaliação do conhecimento tático processual de orientação esportiva (TCTP-OE), por meio do cálculo do coeficiente de validade de conteúdo proposto por Hernández-Nieto (2002). Este procedimento também foi aplicado nos estudos de validação de questionário de valores olímpicos (QVO-27) (Secco et al., 2009), protocolo de categorização de metodologias de ensino nos desportos (Soares, Santos, Lima, Aburahcid, \& Greco, 2010), escala de autopercepção para crianças (Valentini, Villwock, Vieira, Vieira, \& Barbosa, 2010) e cenas de teste de ténis (Aburachid \& Greco, 2011).

A validade de conteúdo foi uma das validades internas realizadas junto a outros procedimentos aplicados posteriormente, tais como, a verificação da dimensionalidade, da fidedignidade e da validade de construto.

\section{MÉTODO}

\section{Amostra}

Os procedimentos de validade de conteúdo seguiram os passos metodológicos apresentados por Hernández-Nieto (2002) através da avaliação de 11 juízes (4 de basquetebol, 3 de andebol e 4 de futsal), respeitando o número mínimo de três e máximo de cinco juízes por modalidade desportiva, como recomendado por este autor. Além disso, conforme Balbinotti, Benetti e Terra (2006) os juízes não podem participar de nenhuma parte do processo de pesquisa e acumular experiência ativa de no mínimo 10 anos na área, neste caso, na área dos JDC. No presente estudo os peritos tinham experiência profissional em diferentes categorias e níveis de rendimento.

Uma primeira versão do Teste de Conhecimento Tático Processual: Orientação Esportiva (TCTP-OE) foi estabelecida a partir das ações táticas confirmadas por meio do cálculo do coeficiente de validade de conteúdo (CVC). Essa foi aplicada na avaliação do conhecimento tático processual em 321 crianças de ambos os sexos, praticantes e não praticantes de "escoli- nhas desportivas", com média de idades de $10.32 \pm 1.45$ anos. Para a computação das ações foram analisados 108 jogos simulados (isto é, joga-se $3 \times 3$ conforme descrito a seguir), sendo que um mesmo sujeito foi avaliado por duas vezes, realizando o jogo com os pés e com as mãos.

O projeto foi aprovado pelo Comitê de Ética em pesquisa da Universidade Federal de Minas Gerais sob o número CAAE - 0734.0.203.00012. Foi obtido para todos os participantes deste estudo o respetivo Termo de Consentimento Livre e Esclarecido assinado pelos pais ou seus tutores.

\section{Consolidação das ações desportivas}

As ações desportivas foram elencadas a partir de ações tático-técnicas realizadas com as mãos e os pés. Semelhantemente à aplicação do teste Game-test situations (GTS) de Memmert e Roth (2003) (aplicado durante 3 minutos, em um quadrado de $9 \times 9$ metros, com dois grupos de $3 \times 3$ jogadores num mesmo espaço), a proposição de nova validação partirá dessa mesma situação, porém alterando a duração do teste para 4 minutos em sua forma de execução. Para isso, a troca de passes será realizada de maneira contínua e caso os jogadores na defesa recuperem a posse de bola, deverão iniciar imediatamente a troca de passes (ataque). Dessa maneira, o teste possibilita uma situação semelhante a como acontece nas modalidades desportivas coletivas.

Os desportos mais associados à verificação das ações esportivas são: futsal utilizando os pés, e andebol e basquetebol utilizando as mãos. Caracterizam-se pela prática num espaço comum, com ações simultâneas entre ataque e defesa, o que permite distingui-las a partir das fases do jogo em ofensivas, defensivas e de transição (contra-ataque e reorganização de defesa) (Bayer, 1986). O voleibol não se adequa como um desporto para a construção desse teste porque a estrutura do jogo inclui a rede, classificando-se como desporto de rede/ parede e de prática do jogo em espaço separado (Griffin et al.,1997; Moreno, 1994). 
As 18 ações esportivas de observação do TCTP-OE propostas inicialmente para compor o instrumento e avaliar o comportamento tático-técnico dos sujeitos, tiveram como base a classificação espacial e comportamental, as fases do jogo, assim como a posse ou não da bola. Sendo assim, os pesquisadores do Centro de Estudos de Cognição e Ação criaram as ações esportivas incutidas nas seguintes dimensões:

- Jogador no ataque sem bola (JSB);

- Jogador no ataque com bola (JCB);

- Marcação ao jogador sem bola (MJSB);

- Marcação ao jogador com bola (MJCB).

O critério definido para a computação das ações consiste do registo da frequência com que esses comportamentos são observados. Ou seja, na análise dos vídeos os observadores registam cada ação tático-técnica realizada pelos sujeitos nesses jogos simulados contidos nos quatro itens que compõem cada dimensão identificados de um a dezasseis (ver tabela 5).

\section{Procedimentos de validade de conteúdo}

Conforme sugerido por Pasquali (2003), objetivou-se nesta etapa do procedimento de validação testar, de maneira teórica, a hipótese do pesquisador. Ou seja, os itens construídos representam adequadamente o construto? A análise de conteúdo antecede a análise de construto, pois se procura verificar a adequação da representação comportamental do(s) atributo(s) latente(s).

O coeficiente de validade de conteúdo (CVC) mede o grau de concordância entre os juízes a respeito de cada item e vem preencher a lacuna das propriedades métricas do teste estatístico Kappa Cohen, que avalia apenas a fidedignidade e consistência (Balbinotti, 2005; Hernández-Nieto, 2002;). As instruções de avaliação dos itens propostas aos peritos incluíram uma escala de Likert de 5 pontos, além de permitir aos mesmos comentários livres sobre cada ação desportiva. A explanação dos critérios para escolha das ações táticotécnicas se apresenta a seguir.

\section{Clareza de Linguagem}

Avaliou a linguagem escrita das ações, levando-se em conta a compreensão da forma como as ações poderão ser executadas em movimento. Foram apresentadas as seguintes questões aos peritos: "As ações são compreensíveis quanto à execução de movimento? É possível imaginar e executar esta ação após sua leitura?"

\section{Pertinência prática}

Avaliou as ações esportivas como forma de representar as situações tático-técnicas para a tomada de decisão no jogo. Foram apresentadas as seguintes questões aos peritos: "Você acredita que estas ações representam situações que realmente ocorrem no momento que um jogador atua em jogo?"

\section{Relevância teórica}

Avaliou a relevância das ações como forma de demonstração dos processos cognitivos que se tinha interesse de avaliar. Pergunta feita aos peritos: "Você acredita que estas ações esportivas permitem a análise da tomada de decisão tático-técnica de um jogador?"

Hernández-Nieto (2002), Balbinotti et al. (2006) e Pasquali (1999) recomendam que os itens do instrumento devam apresentar um valor mínimo de CVC igual a 0.80 . Com relação à clareza de linguagem, caso o item apresente valores inferiores a 0.80 , os autores preconizam que a linguagem seja reformulada antes que a bateria de testes seja administrada à população alvo. Em relação à relevância teórica, para este estudo os itens com valores inferiores a 0.80 também foram reformulados, conforme as sugestões e observações dos juízes para que se enquadrassem na formulação do instrumento posteriormente proposto. Os itens julgados como insatisfatórios no termo da pertinência prática foram rechaçados na análise dos resultados do exame.

\section{Aplicação do TCTP-OE}

O TCTP-OE foi aplicado por professores de educação física com experiência no processo de 
ensino-aprendizagem nas modalidades desportivas coletivas. Para isso, todas as ações táticotécnicas dos participantes realizadas com as mãos e com os pés foram filmadas durante a realização da situação de jogo de $3 \times 3$. O conhecimento tático processual foi avaliado, por meio das ações tático-técnicas que alcançaram valores satisfatórios de validade de conteúdo (CVC $\geq 0.80)$. Foi necessária a realização do treino de dois observadores por meio de análise de vídeos do jogo simulado junto aos pesquisadores responsáveis. Dessa maneira, foi possível tirar as dúvidas que surgiram e alinhar o entendimento em relação à aplicação dos critérios de observação.

\section{Análise Estatística}

As escalas respondidas foram inseridas e analisadas no programa Microsoft Office Excel 2010 através da fórmula do CVC. A análise dos dados foi computada a partir das fórmulas específicas apresentadas a seguir (Tabela 1).

Tabela 1

Fórmula do CVC e sua descrição

Fórmula do Coeficiente de Validade de Conteúdo (CVC)

\begin{tabular}{c}
$\mathrm{M}_{x=\sum_{x} / \mathrm{J}}$ \\
\hline $\begin{array}{c}\text { Média de cada item: soma dos valores obtidos } \\
\text { na escala de Likert (x) pelo número de juízes }(\mathrm{J})\end{array}$ \\
$\mathrm{CVCi}=\mathrm{M}_{x} / \mathrm{V}_{\text {máx }}$
\end{tabular}

2

CVC do item: média do item pelo valor máximo que o item pode alcançar

$\mathrm{CVCc}=\mathrm{CVCi}-(1 / \mathrm{J})^{\mathrm{J}}$

3

CVCc: CVC do item subtraído da constante (Pei) da fórmula

\section{$\mathrm{CVCt}=\mathrm{Mcvci}-\mathrm{M}(1 / \mathrm{J})^{\mathrm{J}}$}

CVC total: Média do CVC do item subtraído da média da constante

Nota: CVCi - Coeficiente de validade de conteúdo de cada item; CVCc - Coeficiente de validade de conteúdo de cada item subtraído da constante; Pei - Constante da fórmula; CVCt - Coeficiente de validade de conteúdo total do critério

A validade de construto do TCTP-OE foi determinada, por meio da análise fatorial exploratória (AFE). O método utilizado foi o de componentes principais com rotação ortogonal Varimax e normalização Kaiser. Os dados foram analisados por meio do pacote estatístico SPSS ${ }^{\circledR}$ 16.0.

A fiabilidade do TCTP-OE foi estabelecida, por meio do método teste-reteste em dias diferentes (interavaliadores). $\mathrm{O}$ intervalo de tempo entre uma observação e a outra foi de 7 dias. A técnica usada foi a correlação intraclasse (ICC), considerando no mínimo $10 \%$ da amostra total. Para este estudo 154 participantes foram reavaliados, configurando $27 \%$ da amostra (Tabachnick \& Fidell, 1989).

\section{RESULTADOS}

Os resultados deste estudo se apresentam a partir dos valores de CVCtotal para os critérios de validação (clareza da linguagem, pertinência prática e relevância teórica) avaliados pelos juízes no basquetebol (Tabela 2). Nos três critérios o CVCtotal foi satisfatório, levando-se em consideração a nova aceitação do item 11 (Apoia aos colegas na defesa - cobertura quando são superados pelo adversário) e o descarte dos itens 5 e 8.

$\mathrm{Na}$ Tabela 3 observam-se os valores de CVCtotal para os critérios de validação levando-se em consideração a modalidade andebol. O CVCtotal dos três critérios foi satisfatório, exceto na clareza da linguagem. Os itens de número 1 a 11 , que em primeira instância obtiveram valores de CVCt de 0.79 , foram reavaliados e aceites em nova análise do painel de juízes, com CVCt de 0.80 .

Os valores de CVCtotal para os critérios de validação na modalidade futsal estão evidenciados na Tabela 4. Nos três critérios, o CVCtotal foi satisfatório, levando-se em consideração a nova aceitação dos itens 1, 2, 11 e 17 e o descarte dos itens 3, 4 e 5. Mesmo que o item 4 tenha sido aceito no critério de relevância teórica após sua reformulação, no critério pertinência prática foi desconsiderado, o que o excluiu definitivamente do rol de itens válidos.

Após a análise da validade de conteúdo, os itens com CVC baixo $(\leq 0.80)$ na pertinência 
Tabela 2

Cálculo do Coeficiente de Validade de Conteúdo (CVC) para os Critérios no Basquetebol

\begin{tabular}{cccc}
\hline Critérios de validação & CVC total & CVCc reavaliados e aceitos & CVCc eliminados \\
\hline Clareza da linguagem & 0.88 & Item 11 (MJSB): 0.72 & - \\
Pertinência prática & 0.92 & - & Item 5 (JCB): 0.72 \\
Relevância teórica & 0.98 & - & Item 8 (MJSB): 0.72 \\
\hline Nota: (JCB) Jogador no ataque com bola; (MJSB) Marcação ao jogador sem bola & -
\end{tabular}

Tabela 3

Cálculo do Coeficiente de Validade de Conteúdo (CVC) para os Critérios no Andebol

\begin{tabular}{cccc}
\hline Critérios de validação & CVC total & CVCc reavaliados e aceitos & CVCc eliminados \\
\hline Clareza da linguagem & 0.80 & Item 1 a 11 & - \\
Pertinência prática & 0.94 & (JSB, JCB, MJCB): 0.72 & - \\
Relevância teórica & 0.95 & - & - \\
\hline
\end{tabular}

Nota: (JCB) Jogador no ataque com bola; (JSB) Jogador no ataque sem bola; (MJCB) Marcação ao jogador com bola

Tabela 4

Cálculo do Coeficiente de Validade de Conteúdo (CVC) para os Critérios no Futsal

\begin{tabular}{cccc}
\hline Critérios de validação & CVC total & CVCc reavaliados e aceitos & CVCc eliminados \\
\hline & & Item 1 e 2 (JSB, JCB): 0.70 & -
\end{tabular}

$\begin{array}{lccc}\text { Pertinência prática } & 0.87 & - & \text { Item } 3 \text { (JSB): } 0.75 \\ \text { Relevância teórica } & 0.94 & \text { Item } 4 \text { (JSB): } 0.75 \\ \text { Item 4 (JSB): } 0.70 & \text { Item 5 (JCB): } 0.70\end{array}$

Nota: (JCB) Jogador no ataque com bola; (JSB) Jogador no ataque sem bola; (MJCB) Marcação ao jogador com bola; (MJSB) Marcação ao jogador sem bola

prática foram retirados do instrumento proposto, por não serem ações tático-técnicas típicas dos JDC de invasão (basquetebol, andebol e futsal), que são o foco deste estudo. Foram eles: item 3 (Afasta-se do portador da bola criando linhas de passe sem prejudicar sua progressão), item 4 (Aproxima-se do portador da bola criando linhas de passe sem prejudicar sua progressão), item 5 (Finta e avança/dribla ou passa a bola) e item 8 (Passa ao colega sem marcação e desloca em sua direção para passar pelas costas e receber).

$\mathrm{O}$ rol das ações a serem visualizadas em forma de ocorrências no teste piloto, próximo passo da validação, foi finalizado com 16 ações desportivas tático-técnicas, agora intituladas itens.

Embora tenham sido retirados quatro itens dos 18 propostos, optou-se por criar um novo item em substituição ao item 4 , assim como a reformulação do item 15 (Pressiona ao adversário tentando tirar a bola ou induzindo ao erro). Pela avaliação dos juízes o item 4 (Procura espaços livres executando deslocamentos com mudanças de direção e de velocidade) deveria ser parte da dimensão de marcação ao jogador com bola (MJCB) e não sem bola, como havia sido proposto pelos pesquisadores. 
Tabela 5

Teste de Conhecimento Tático Processual para Orientação Esportiva após o cálculo do CVC

Teste de Conhecimento Tático Processual: Orientação Esportiva

Ações Técnico-Táticas No Ataque: Jogador Sem Bola (JSB)

1 Movimenta-se procurando receber a bola

2 Movimenta-se sem intenção de procurar a bola

3 Procura espaços livres executando deslocamentos sem mudanças de direção e de velocidade

4 Procura espaços livres executando deslocamentos com mudanças de direção e de velocidade

Ações Técnico-Táticas No Ataque: Jogador Com Bola (JCB)

5 Protege a bola com a intenção de não perder a posse ou para realizar um passe.

6 Dribla controlando a bola (fazendo ou não finta) com a intenção de executar um passe.

7 Passa ao colega sem marcação e posiciona-se para receber

8 Passa ao colega com marcação e posiciona-se para receber

Ações Técnico-Táticas Na Defesa: Marcação ao Jogador Sem Bola (MJSB)

9 Acompanha os deslocamentos do adversário que tenta se desmarcar

10 Desloca-se para interceptar ou antecipar o passe

11 Apóia aos colegas na defesa (cobertura) quando são superados pelo adversário

12 Apóia ao colega na defesa quando o jogador com bola tem dificuldade para dominá-la

Ações Técnico-Táticas na Defesa: Marcação ao Jogador Com Bola (MJCB)

13 Marca à distância mantendo o controle visual do jogador com bola

14 Pressiona ao adversário e acompanha seus deslocamentos

15 Pressiona ao adversário tentando tirar a bola ou induzindo ao erro

16 Pressiona ao adversário levando-o para os cantos do campo de jogo

Dessa maneira e conforme os ajustes, o instrumento final comtemplou quatro itens para cada dimensão (jogador no ataque sem bola JSB, jogador no ataque com bola - JCB, marcação ao jogador sem bola - MJSB e marcação ao jogador com bola - MJCB), totalizando 16 itens a serem observados na Tabela 5 .

Em relação à validade de construto o TCTPOE executado com a mão, a AFE identificou seis itens que carregaram satisfatoriamente em um dos dois fatores definidos pela regra de Kaiser (componente $1=2.630$ e $43.83 \%$ de variância explicada e componente $2=1.341 \mathrm{e}$ $22.35 \%$ de variância explicada). Nesse contexto, o item 1 (Movimenta-se procurando receber a bola - JSB) e item 7 (Passa ao colega sem marcação e posiciona-se para receber - JCB), relacionados com ações no ataque sem bola e com bola apresentaram carga fatorial satisfatória no fator 2. O item 11 (Apoia aos colegas na defesa "cobertura" quando são superados pelo adversário - MJSB), item 12 (Apoia ao colega na defesa quando o jogador com bola tem dificuldade para dominá-la - MJSB), item 14 (Pressiona ao adversário e acompanha seus deslocamentos - MJCB) e item 16 (Pressiona ao adversário levando-o para os cantos do campo de jogo - MJCB), relacionados a situações de defesa marcando ao jogador no ataque sem bola e com bola, carregaram satisfatoriamente no fator 1. Assim, os pesquisadores optaram por denominar o fator 1 de defesa e o fator 2 de ataque. A percentagem total de variância explicada pelo modelo final alcançado foi de $66.18 \%$.

$\mathrm{O}$ valor do KMO calculado com os cinco itens que apresentaram cargas fatoriais satisfatórias no modelo final resultante foi de 0.74 , indicando que a técnica da análise fatorial pode ser utilizada para a amostra em questão. A 
prova de esfericidade de Bartlett demonstrou que existem correlações significativas (Quiquadrado $=883.28, d f=15, p<0.001)$ entre as variáveis e o modelo fatorial é pertinente.

A AFE do TCTP-OE executada com o pé identificou cinco itens que carregaram satisfatoriamente em um dos dois fatores definidos pela regra de Kaiser (componente $1=2.101 \mathrm{e}$ $42.01 \%$ de variância explicada e componente $2=1.256$ e $25.12 \%$ de variância explicada). Portanto, os itens 1 (Movimenta-se procurando receber a bola - JSB) e 7 (Passa ao colega sem marcação e posiciona-se para receber - JCB), relacionados com ações no ataque sem bola e com bola apresentaram carga fatorial satisfatória no fator 2. Os itens 11 (Apoia aos colegas na defesa "cobertura" quando são superados pelo adversário - MJSB), 12 (Apoia ao colega na defesa quando o jogador com bola tem dificuldade para dominá-la - MJSB) e 16 (Pressiona ao adversário levando-o para os cantos do campo de jogo - MJCB), relacionados a situações de defesa marcando ao jogador no ataque sem bola e com bola, carregaram satisfatoriamente no fator 1. Dessa maneira, os pesquisadores optaram por denominar o fator 1 de defesa e o fator 2 de ataque. A percentagem total de variância explicada pelo modelo final alcançado foi de $67.13 \%$.

$\mathrm{O}$ valor do KMO calculado com os cinco itens que apresentaram cargas fatoriais satisfatórias no modelo final resultante foi de 0.63 , indicando que a técnica da análise fatorial pode ser utilizada para a amostra em questão. A prova de esfericidade de Bartlett demonstrou que existem correlações significativas (Quiquadrado $=405.68, d f=10, p<0.001)$ entre as variáveis e o modelo fatorial é pertinente.

No que se refere à fidedignidade do TCTPOE, os valores do ICC calculados foram satisfatórios (ICC $=0.40-0.74)$ e excelentes (ICC $\geq$ 0.75) determinando a fidedignidade do instrumento (Szklo \& Nieto, 2000). Portanto, para a situação JSB os valores foram de 0.74 para mão e 0.76 para pé. Na situação JCB os valores foram de 0.77 para mão e 0.79 para pé. $\mathrm{Na}$ situação MJSB os valores foram de 0.72 para mão e 0.67 para pé. Na situação MJCB os valores foram de 0.76 para mão e 0.73 para pé.

\section{DISCUSSÃO}

Como o objetivo deste trabalho foi avaliar a utilização do método de validade de conteúdo para validar ações para a composição de um teste de orientação desportiva, a avaliação dos juízes permitiu resultados satisfatórios quanto à manutenção de 16 itens que representam ações desportivas tático-técnicas. Este número representativo de itens $88.8 \%$ contribuiu para verificar que os processos cognitivos e motores utilizados para a execução dessas ações se baseiam na classificação das fases do jogo propostas por Bayer (1986). Além disso, pôde-se perceber semelhanças entre as ações desportivas, mesmo que estas sejam realizadas com os pés ou com as mãos, o que se apoiou nas teorias de classificação dos desportos de Griffin et al. (1997) e Moreno (1994).

Em sua maioria, as ações desportivas apresentaram relevância teórica e uma linguagem clara, que se define como a compreensão das ações que ocorrem em movimento no jogo interpretadas por meio da leitura da linguagem escrita. Os fatores limitantes nos valores de corte na validação evidenciaram-se no critério de pertinência prática, o que já era esperado. Como a pertinência prática se caracteriza pela forma de representação das situações táticotécnicas para tomada de decisão no jogo, existe uma representativa dificuldade semântica para se definir o conceito deste tipo de ações no âmbito desportivo. Como exemplo apresentase a situação do drible: driblar no futsal é considerado fintar, ou seja, realizar movimentos com o corpo (com ou sem bola) para enganar o adversário. Já no basquetebol e no andebol, o driblar significa ressaltar a bola em deslocamento ou parado.

O bloqueio no andebol é outro exemplo discrepante entre as modalidades, pois no basquetebol e no futsal é nomeado como "corta luz" (bloquear com o corpo a movimentação do adversário para que seu companheiro de equipe tenha espaço livre para finalizar). 
Vale ressaltar que a concretização das ações desportivas a serem validadas por seu conteúdo serão úteis tanto para avaliar a aprendizagem dos alunos quanto para, através da verificação de ocorrência ou não das mesmas, ofertar o maior uso dessas ações nas sessões de treinos per se. O instrumento a ser validado pretende ser mais do que uma avaliação ou uma mensuração do produto esperado de uma unidade pedagógica (Harvey \& Van Der Mars, 2010). O instrumento deve alcançar uma perspetiva de aprendizagem, permitindo que os alunos demonstrem suas técnicas e conhecimento tático que poderão ser aplicados no contexto do mundo real.

Os valores de corte dos estudos de Pasquali (1999), Balbinotti et al. (2006) e HernándezNieto (2002) foram mantidos, com $\mathrm{CVC} \geq 0.80$, sugerindo que o rol de ações tático-técnicas desportivas selecionadas fosse pertinente baseada numa análise de forma empírica.

Acredita-se que a validação de construto dos itens embasada na teoria psicométrica de Pasquali (2003) cobriu grande parte significativa da extensão semântica do construto. A partir de uma sequência de estudos realizados na área da Educação Física (Aburachid \& Greco, 2011; Secco et al. 2009; Soares et al. 2010; Valentini et al. 2010;) torna-se possível comprovar, mais uma vez, que os procedimentos estatísticos de Hernández-Nieto (2002) para a validação de conteúdo se adequam a esta área.

\section{CONCLUSÕES}

A hipótese de validar um número satisfatório de ações tático-técnicas, ocorrentes em jogos coletivos, para a criação de um instrumento de avaliação do conhecimento tático processual, voltado à orientação desportiva, pôde ser confirmada após a aplicação do CVC. Demonstrou-se que este método também se ajusta na validação de ações a serem realizadas em avaliações processuais.

Este tipo de desafio contribui para um processo criterioso de validação e será utilizado como meio pedagógico, para a unificação conceitual das ações tático-técnicas nos desportos coletivos. A aplicação do TCTP-OE permitirá planificar os processos de ensino-aprendizagem das capacidades do rendimento desportivo relacionadas à cognição e ação, bem como aplicar avaliações temporais dentro dos períodos de treino adequando a regulação desse processo, seja na formação ou na descoberta de talentos desportivos. A utilização deste teste universaliza o conceito e execução das ações ocorrentes no jogo, o que facilita para o professor/treinador aplicar o instrumento e saber interpretá-lo. Torna-se possível avaliar o conhecimento tático processual nas modalidades desportivas coletivas de invasão, particularmente basquetebol, andebol e futsal, por meio de um teste simples, de baixo custo, aplicável em diferentes níveis de rendimento. Recorrendo ao solicitado por Harvey e Van Der Mars (2010), o TCTP-OE apresenta situações reais de jogo que são avaliadas e assim, diretamente relacionadas com os conteúdos do ensino dos jogos, e integrá-los na elaboração de processos de ensino-aprendizagem-treino mais precisos, direcionados ao desenvolvimento das potencialidades dos praticantes.

Dos 16 itens validados no TCTP-OE por meio do cálculo do CVC, a AFE confirmou 6 itens com a mão e 5 itens com o pé, configurando a segunda e definitiva versão do teste. Pode-se afirmar que as ações tático-técnicas, definidas na AFE, são suficientes para avaliar o conhecimento tático processual na iniciação desportiva nas modalidades desportivas de basquetebol, futsal e andebol.

Recomenda-se que os interessados em aplicar o teste compreendam a interpretação das ações de forma universal e que as mesmas sirvam como ações inclusive a serem estimuladas no processo de ensino-aprendizagem.

\section{Agradecimentos:}

Nada a declarar.

Conflito de Interesses:

Nada a declarar. 
Financiamento:

Conselho Nacional de Desenvolvimento Científico e Tecnológico (CNPq).

\section{REFERÊNCIAS}

Aburachid, L.M.C., \& Greco, P.J. (2011). Validação de conteúdo de cenas do teste de conhecimento tático no tênis. Estudos de Psicologia (Campinas), 28(2), 261-267. doi: 10.1590/S0103-166X2011 000200013

Anderson, J.R. (1987). Skill acquisition: Compilation of weak-method problem solutions. Psychological Review, 94, 192-210.

Balbinotti, M.A., Benetti, C., \& Terra, P.R. (2006). Translation and validation of the GrahamHarvey survey for the Brazilian context. International Journal of Managerial Finance, 3, 26-48. doi: 10.1590/S0103-166X2011000200013

Balbinotti, M.A. (2005). Para se avaliar o que se espera: Reflexões acerca da validade dos testes psicológicos. Aletheia, 21, 43-52.

Bayer, C. (1986). La enseñanza de los juegos deportivos colectivos. Barcelona: Hispano Europea.

Blomqvist, M., Luhtanen, P., Laakso, L., \& Keskinen, E. (2000). Validation of a video based game understanding test procedure in badminton. Journal of Teaching in Physical Education, 19(3), 325-337. doi: 10.1080/17408989.2010. 535202

Blomqvist, M., Vänttinen, T., \& Luhtanen, P. (2005). Assessment of secondary scholl student's decision-making and game-play ability in soccer. Physical Education and Sport Pedagogy, 10(4), 107-119. doi: 10.1080/1740898050010 4992

Costa, I.T., Garganta, J., Greco, P.J., Mesquita, I., \& Maia, J. (2011). Sistema de Avaliação Táctica no Futebol (FUT-SAT): Desenvolvimento e Validação Preliminar. Motricidade, 7(1), 69-84. doi: 10.6063/motricidade.7(1).121

Costa, J.C., Garganta J., Fonseca, A., \& Botelho, M. (2002). Inteligência e conhecimento específico em jovens futebolistas de diferentes níveis competitivos. Revista Portuguesa de Ciências do Desporto, 2(4), 7-20.

Garganta, J. (1995). Para uma teoria dos Jogos Desportivos Colectivos. In A. Graça \& J. Oliveira (Ed.), O ensino dos jogos desportivos (pp. 11-25). Porto: CEJD/FCDEF-UP.
Greco, P., Memmert, D., \& Morales, J.C. (2010). The effect of deliberate play on tactical performance in basketball. Perceptual Motor Skills, 110(3) 849-856. doi: 10.2466/pms.110.3.849856

Gréhaigne, J.F., Godbout, P., \& Bouthier, D. (1997). Performance assessment in team sports. Journal of Teaching in Physical Education, 16 (4) 500-516.

Griffin, L.L., Mitchell, S.A., \& Oslin, J.L. (1997). Teaching sport concepts and skills: A tactical games approach. Champaign: Human Kinetics.

Harvey, S., \& Van Der Mars, H. (2010). Teaching and assessing racquet games using "play practice" - part 2 - Integrating assessment into teaching: Linking instruction with assessment promotes student learning. The Journal of Physical Education, Recreation \& Dance, 81 (5), 1-14.

Hernández-Nieto, R.A. (2002). Contributions to statistical analysis. Mérida: Universidad de Los Andes.

Mcpherson, S.L., \& Thomas, J.R. (1989). Relation of knowledge and performance in boys' tennis: Age and expertise. Journal of Experimental Child Psychology, 48(2), 190-211. doi: 10.1016/00220965(89) 90002-7

Memmert, D., \& Roth, K. (2003). Individual taktische Leistungsdiagnostik im Sportspiel. Spektrum der Sportwissenschaft, 15(1), 44-70.

Mitchell, S.A., \& Oslin, J.L. (1994). An investigation of tactical transfer in net games. European Journal of Physical Education, 4(2), 162-172. doi: 10.1080/1740898990040205

Moreno, J.H. (1994). Fundamentos del deporte: Analisis de las estructuras del juego deportivo ( $\left.2^{\mathrm{a}} \mathrm{ed}\right)$. Barcelona: INDE.

Nitsch, J.R. (2009). Ecological approaches to sport activity: A commentary from an actiontheoretical point of view. International Journal of Sport Psychology, 40, 152-176.

Oslin, J.L., Mitchell, S.A., \& Griffin, L.L. (1998). The Game Performance Assessment Instrument (GPAI): Development and Preliminary Validation. Journal of Teaching in Physical Education, 17, 231-243.

Pasquali, L. (1999). Instrumentos Psicológicos: Manual prático de elaboração. Brasília: Prática Gráfica e Editora Ltda.

Pasquali, L. (2003). Psicometria: Teoria dos testes na psicologia e na educação. Petrópolis: Vozes.

Secco, V.G., Santos, F.P., Costa, C.P., Todt, N.S., Saldanha, R.P., \& Silva, L.H. (2009). Educação Olímpica: Avaliação da validade de conteúdo do "Questionário de Valores Olímpicos (QVO-27)". 
Comunicação apresentada no X Salão de Iniciação Científica PUCS, Porto Alegre, Brasil.

Soares, V., Santos, H., Lima, M., Aburahcid, L., \& Greco, P. (2010). Validação de protocolo de categorização de metodologias de ensino nos esportes coletivos com base na Iniciação Esportiva Universal - uma escola da bola. Lecturas: Educación Física y Deportes, 15, 144.

Szklo, M., \& Nieto, F.J. (2000). Epidemiology beyond the basics. Maryland: ASPEN Publishers.

Tabachnick, B., \& Fidell, L. (1989). Using multivariate statistics. New York: Harper \& Row Publishers.
Valentini, N.C., Villwock, G., Vieira, L.F., Vieira, J.L., \& Barbosa, M.L. (2010). Validação brasileira da escala de autopercepção de Harter para crianças. Psicologia: Reflexão e Crítica, 23(3) 411419. doi: 10.1590/S0102-79722010000300001

Williams, A., Ward, P., \& Smeeton, N. (2004). Perceptual and cognitive expertise in sport: Implications for skill acquisition and performance enhancement. In A. Williams \& $\mathrm{N}$. Hodges (Eds.), Skill acquisition in sport: Research, theory and practice (pp. 328-347). London: Routledge. quando especificado em contrário e nos conteúdos retirados de outras fontes bibliográficas. 